\title{
N-Doped Animal Keratin Waste Porous Biochar derived from Trapa Natans Husks
}

\author{
Wenjun Yin ${ }^{1,2, *}$, Zhonghua Zhang ${ }^{3}$, Tongcai Liu ${ }^{1}$, Jiao $\mathrm{Xu}^{1}$, Shaoze $\mathrm{Xiao}^{1}$ and Yao $\mathrm{Xu}^{1, *}$ \\ 1 State Key Laboratory of Pollution Control and Resource Reuse, College of Environmental Science and \\ Engineering, Tongji University, Shanghai 200092, China; water_tcliu@tongji.edu.cn (T.L.); \\ 1911421@tongji.edu.cn (J.X.); 1810827@tongji.edu.cn (S.X.) \\ 2 UN Environment-Tongji Institute of Environment for Sustainable Development (IESD), Tongji University, \\ Shanghai 200092, China \\ 3 National Engineering Research Center of Protected Agriculture, Tongji University, Shanghai 200092, China; \\ 1833039@tongji.edu.cn \\ * Correspondence: yinwenjun1991@tongji.edu.cn (W.Y.); xuyao0415@tongji.edu.cn (Y.X.); \\ Tel.: +86-132-5674-1911 (W.Y.); +86-188-6218-5393 (Y.X.)
}

Received: 5 February 2020; Accepted: 21 February 2020; Published: 22 February 2020

check for updates

\begin{abstract}
Animal-keratin-wastes (AKWs), horns (HN), hair (HR), puffed waterfowl feathers (PF), hydrolyzed waterfowl feathers (HF), hydrolyzed fish meal (HM), crab meat (CM), feathers (FR), shrimp chaff (SC), fish scales (FS), and waste leather (WL) were used as modifiers to prepare animal-keratin-wastes biochars (AKWs-BC) derived from Trapa natans husks (TH). AKWs-BC have a well-developed microporous structure with a pore size mainly below $3 \mathrm{~nm}$. Due to the doping of AKWs, the surface chemical properties of AKWs-BC (especially $\mathrm{N}$ functional groups) were improved. The utilization of APWs not only realizes the resource utilization of waste, but also can be used to prepare high-performance biochars.
\end{abstract}

Keywords: animal-keratin-waste (AKWs); biochars; N/O functional groups

\section{Introduction}

At present, strong oxidants, nitrogen compounds, metal salts, and other chemical modifiers are mainly used for the modification of surface chemical functional groups of biochar [1,2]. However, chemical modifiers have the disadvantages of being high-cost and having secondary pollution. More than 5 million tons of animal-keratin-waste (AKWs) is produced each year in the world [3]. AKWs are single-fiber crosslinked structural proteins (S-S) with intramolecular and intermolecular disulfide bonds (S-S) [4]. AKWs represent renewable biopolymers that can be better utilized. However, there is a relative lack of information about the possibility of using AKWs as bio-modifiers to prepare biochar. During pyrolysis, the formation of novel radicals is produced by AKWs decomposition, which can react with precursors to produce certain new ester salts and promote the formation of new functional groups. Therefore, we used ten common AKWs (Table 1 and Figure 1), including horns $(\mathrm{HN})$, hair (HR), puffed waterfowl feathers (PF), hydrolyzed waterfowl feathers (HF), hydrolyzed fish meal (HM), crab meat (CM), feathers (FR), shrimp chaff (SC), fish scales (FS), and waste leather (WL), as modifiers to obtain environmentally sustainable biochar with a high surface chemistry. 
Table 1. Textural parameters, amount of acidic and basic functional groups, and elemental compositions of the AKWs-BC and TH-BC.

\begin{tabular}{|c|c|c|c|c|c|c|c|c|c|c|c|}
\hline AKWs & Biochars & $\begin{array}{c}S_{\text {BET }} \\
\left(\mathrm{m}^{2} / g\right)\end{array}$ & $\begin{array}{c}\mathrm{S}_{\operatorname{mic}} \\
\left(\mathrm{m}^{2} / \mathrm{g}\right)\end{array}$ & $\begin{array}{c}V_{\text {tot }} \\
\left(\mathrm{cm}^{3} / \mathrm{g}\right)\end{array}$ & $\begin{array}{c}V_{\text {mic }} \\
\left(\mathrm{cm}^{3} / \mathrm{g}\right)\end{array}$ & $\begin{array}{c}\text { Acidic } \\
(\mathrm{mmol} / \mathrm{g})\end{array}$ & $\begin{array}{c}\text { Basic } \\
(\mathrm{mmol} / \mathrm{g})\end{array}$ & $\begin{array}{c}\mathrm{C} \\
(\%)\end{array}$ & $\begin{array}{c}N \\
(\%)\end{array}$ & $\begin{array}{c}\mathrm{O} \\
(\%)\end{array}$ & $\begin{array}{c}\mathrm{S}+\mathrm{H} \\
(\%)\end{array}$ \\
\hline HR & HR-BC & 1422 & 443 & 1.41 & 0.18 & 3.358 & 1.832 & 72.81 & 1.42 & 23.38 & 2.39 \\
\hline $\mathrm{HF}$ & HF-BC & 1331 & 354 & 1.40 & 0.15 & 3.183 & 1.812 & 75.03 & 1.33 & 21.49 & 2.15 \\
\hline HM & HM-BC & 1342 & 380 & 1.37 & 0.16 & 3.154 & 1.805 & 75.53 & 1.31 & 21.16 & 2.00 \\
\hline $\mathrm{CM}$ & CM-BC & 1301 & 358 & 1.36 & 0.15 & 3.503 & 1.672 & 71.81 & 1.11 & 24.85 & 2.23 \\
\hline FS & FS-BC & 1503 & 438 & 1.55 & 0.17 & 3.294 & 1.752 & 73.93 & 1.28 & 22.69 & 2.1 \\
\hline WL & WL-BC & 1434 & 445 & 1.38 & 0.20 & 3.412 & 1.811 & 72.71 & 1.39 & 23.99 & 1.91 \\
\hline- & TH-BC & 1492 & 491 & 1.49 & 0.20 & 1.426 & 1.423 & 72.38 & 0.42 & 16.35 & 10.85 \\
\hline $\begin{array}{l}\text { variation } \\
\text { coefficients }\end{array}$ & $c_{v}$ & 0.051 & 0.115 & 0.0444 & 0.117 & - & - & - & - & - & \\
\hline
\end{tabular}

(a)

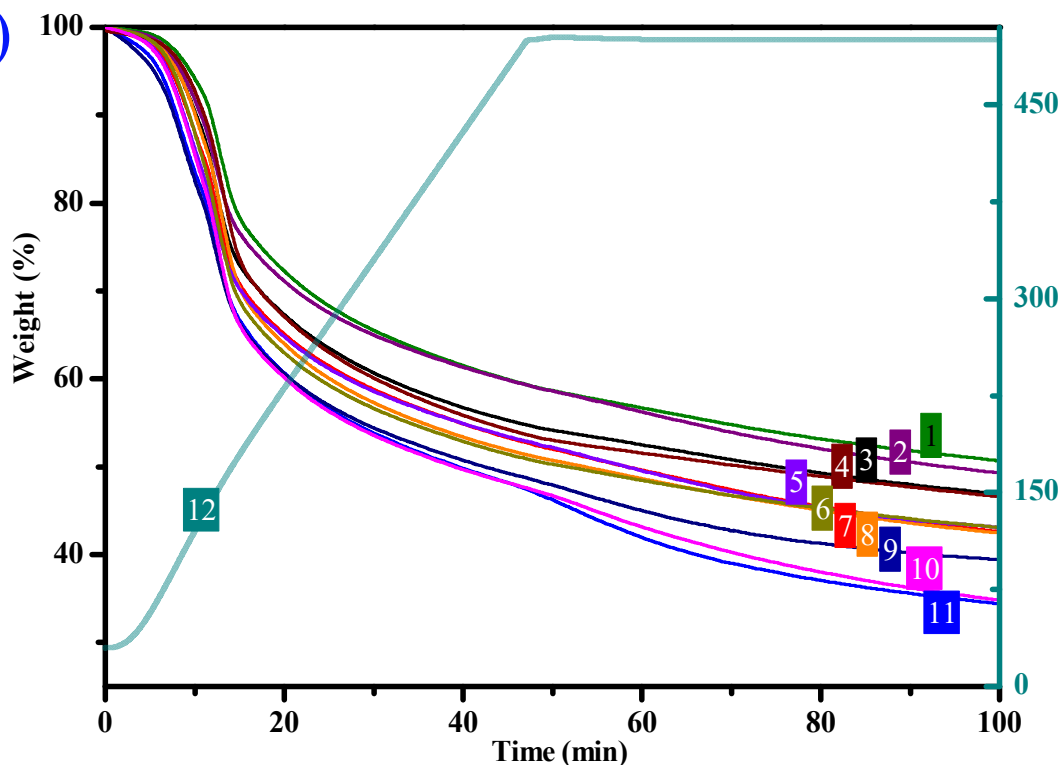

(b)

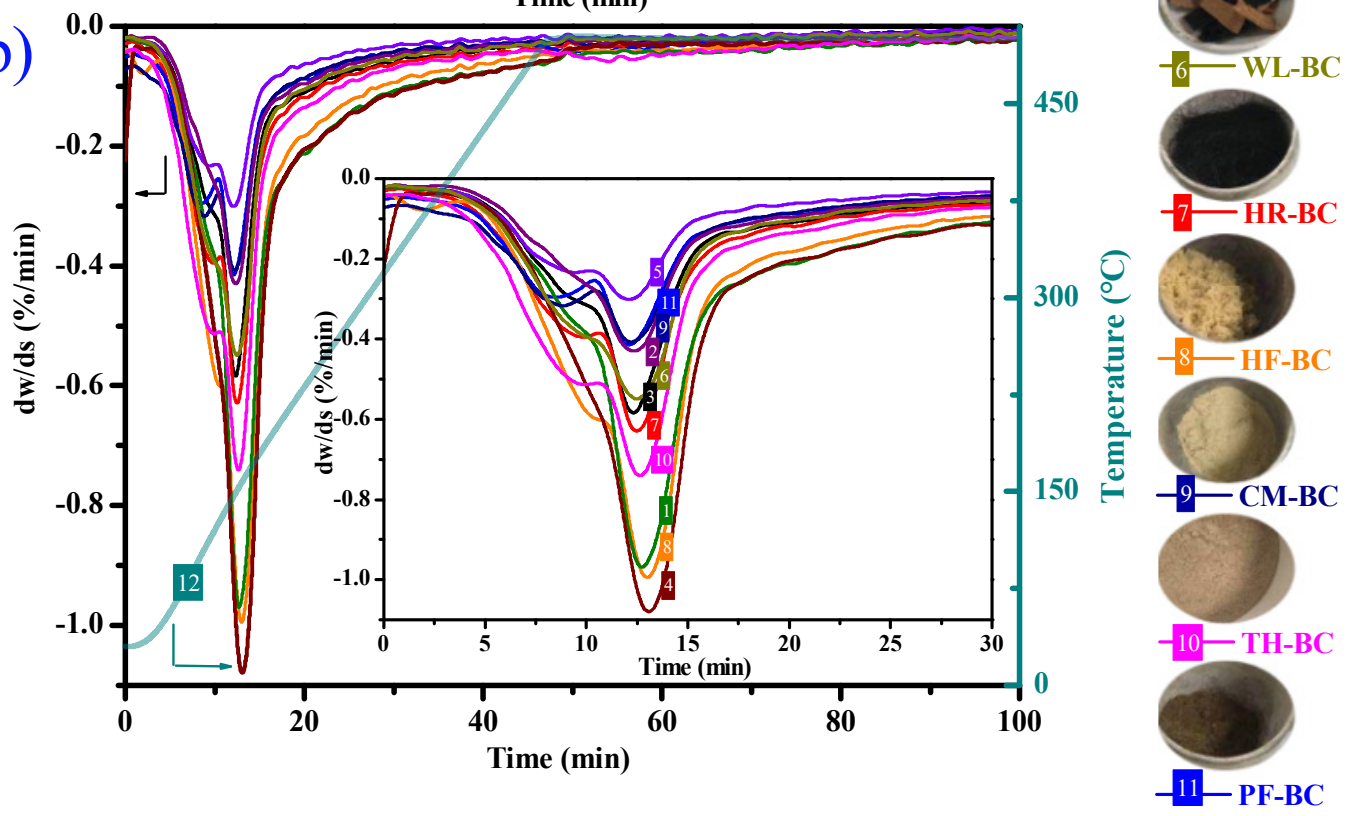

Figure 1. Thermogravimetric analysis (TGA) (a) and differential thermogravimetric analysis (DTG) (b) curves for the pyrolysis of animal-keratin-wastes biochars (AKWs-BC) and TH-based biochar (TH-BC). 


\section{Experimental Materials and Procedures}

Preparation method: All chemicals used were of analytical grade. Trapa natans $(\mathrm{TH})$, containing a large amount of lignin and cellulose, is high-yield waste. TH-based biochar has well developed pore structure and specific surface area. TH (Taihu in Jiangsu, China) and ten groups of AKWs (from one farmers' market in Shanghai, China) were crushed into particle between 0.35 and $1.0 \mathrm{~mm}$. TH was mixed with 10 groups of AKWs, respectively, and the mixed mass ratio was 99:1 (g TH/g AKWs). Each mixture was impregnated with $85 \%$ phosphoric acid (g phosphoric acid/g TH $=2.2: 1$ ) for 10 hours at room temperature. To improve the degree of impregnation, series of pretreatments were used to treat the AKWs: the samples were first soaked in PPA (phosphoric acid, $85 \mathrm{wt} . \%$ ) for $30 \mathrm{~min}$, then irradiated with ultrasound for $20 \mathrm{~min}$, and finally heated at $100{ }^{\circ} \mathrm{C}$ and $1.5 \mathrm{MPa}$ for $30 \mathrm{~min}$ in a vertical automatic electrothermal pressure steam sterilizer. Each of the impregnation slurries was heated to 500 ${ }^{\circ} \mathrm{C}$ (heating rate $=100{ }^{\circ} \mathrm{C} / \mathrm{min}$ ) in a tube furnace and maintained at this temperature for 1 hour under nitrogen protection. Each carbon solid was washed several times with clean water until the $\mathrm{pH}$ of the filtrate was near neutral (about 7). Each carbon solid was dried, ground, and sieved (160-200 mesh). Finally, 10 sets of biochar were obtained: HN-BC, HR-BC, PF-BC, HF-BC, HM-BC, CM-BC, FR-BC, SC-BC, FS-BC, and WL-BC, which were collectively called AKWs-BC. Pure TH-based biochar (TH-BC) was prepared by the same method in Table 1 and Figure 1.

Characterization methods: surface area and pore size distribution were determined by $\mathrm{N}_{2}$ adsorption-desorption at $77 \mathrm{~K}$ with a surface area analyzer (Quanta Chrome Corporation, Mahwah, NJ, USA). Sur-face area $\left(\mathrm{S}_{\mathrm{BET}}\right)$ was measured by the BET (Brunauer-Emmet-Teller equation) method. Pore size distribution was determined by the density functional theory (DFT) method. Micropore volume $\left(\mathrm{V}_{\mathrm{mic}}\right)$ and micropore surface area $\left(\mathrm{S}_{\mathrm{mic}}\right)$ were calculated using the $\mathrm{t}$-plot method. The total pore volume $\left(\mathrm{V}_{\text {tot }}\right)$ was deduced from the manufacturer's software by the BJH theory. The contents of $\mathrm{C}, \mathrm{H}, \mathrm{O}, \mathrm{N}$, and $\mathrm{S}$ of the biochar were measured by a Vario EI III Element Analyzer (Mahwah, NJ, USA). Boehm titration method was used to quantify the acidic and basic functional groups of the biochars. XPS (X-ray photoelectron spectroscopy) analyzer (Nico-let-460, Thermo Fisher, Mahwah, NJ, USA) was conducted to determine the binding energy between electrons and characterize the elements on the surface of biochars.

\section{Experimental Results and Discussion}

Thermogravimetric analysis (TGA) and differential thermogravimetric analysis (DTG) curves for the pyrolysis of AKWs-BC and TH-BC were obtained by TGA-50 analyzer (Figure 1). As shown in the Figure 1, the pyrolysis process of each sample is roughly divided into three decomposition stages. In stage $1\left(0-140^{\circ} \mathrm{C}\right)$, AKWs-BC's weightlessness was greater than that of $\mathrm{TH}-\mathrm{BC}$, which can be explained by the first metamorphic decomposition of keratin [5]. Stage 1 also involved elimination of water vapor and other volatile substances. In stage $2\left(140-500^{\circ} \mathrm{C}\right)$, the new radicals produced by keratin decomposition formed different salt and esters with the thermal hydrolysate of $\mathrm{TH}$ and the heat activator, thereby promoting the formation of functional groups on the surface of the biochar. In stage $3\left(500^{\circ} \mathrm{C}\right)$, the weightlessness of each sample was not significant, indicating formation of the basic structure of biochar.

The pore size distributions (Figure 2a); $\mathrm{N}_{2}$ adsorption/desorption isotherms (Figure $2 \mathrm{~b}$ ); and textural properties of $\mathrm{S}_{\mathrm{BET}}, \mathrm{S}_{\text {mic }}, \mathrm{V}_{\text {mic }}$, and $\mathrm{V}_{\text {tot }}$ (Table 1) of AKWs-BC and TH-BC were obtained by automatic specific surface area and pore size analyzer (GEMINT VII 2390, Mahwah, NJ, USA). As shown in the Figure 2a, both APWs-BC and TH-BC have a narrow pore size distribution $(2-3 \mathrm{~nm})$. As shown in the Figure $2 b$, the isotherms of AKWs-BC and TH-BC were mixture of types I and IV (IUPAC), with small hysteresis loop indicating the presence of well-developed mixed micro-mesopores structure. The variation coefficients in the $\mathrm{S}_{\mathrm{BET}}, \mathrm{S}_{\text {mic }}, \mathrm{V}_{\text {mic }}$, and $\mathrm{V}_{\text {tot }}$ groups were analyzed by SPSS software (Table 1). The low dispersion state of the data within each group indicates that the pore structure characteristics of AKWs-BC and TH-BC are similar. 


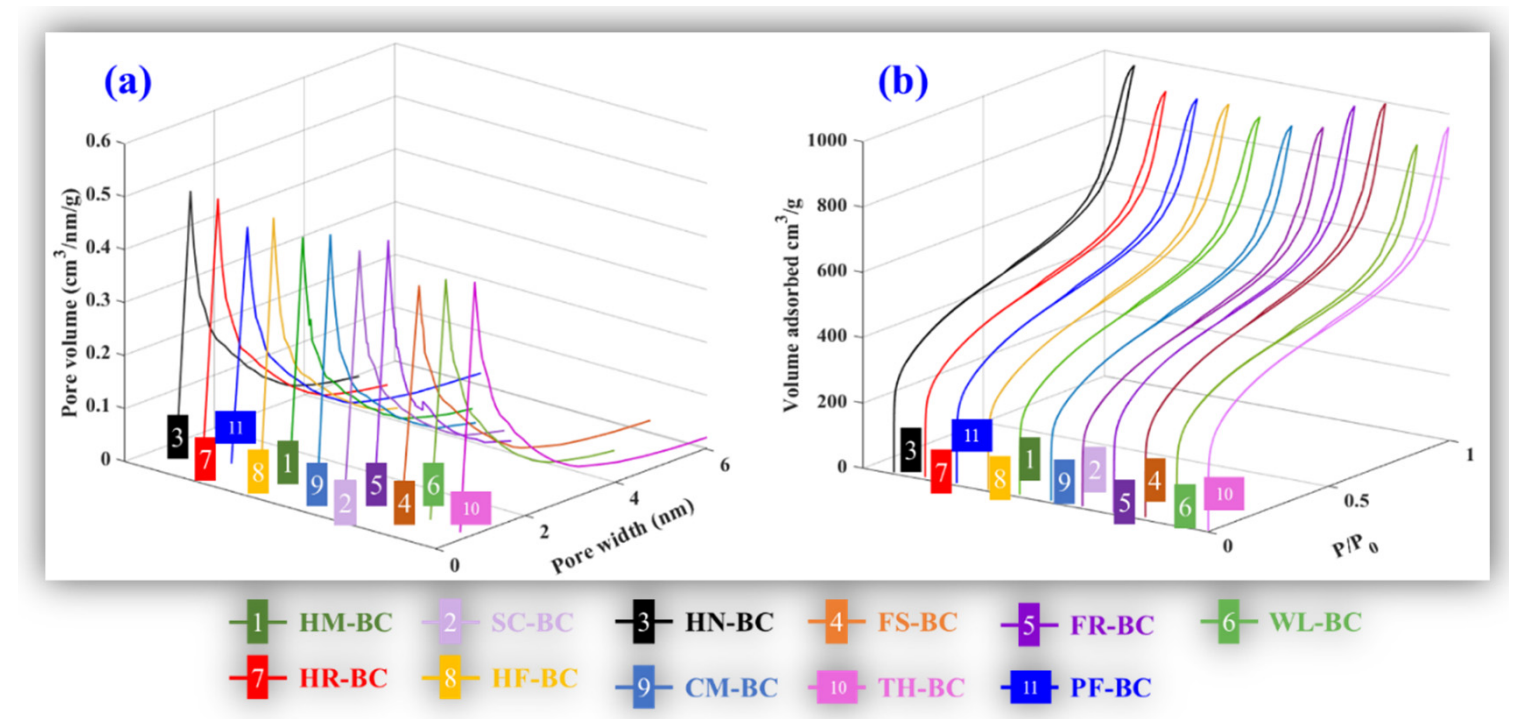

Figure 2. The pore size distributions (a) and $\mathrm{N}_{2}$ adsorption/desorption isotherms (b) of the AKWs-BC and TH-BC.

Boehm's titration results and element composition of the AKWs-BC and TH-BC are shown in Table 1. The percentage content of $\mathrm{O}$ and $\mathrm{N}$ elements in AKWs-BC is increased compared to TH-BC, representing the increase in the content of acidic/basic functional groups on the surface of AKWs-BC. The number of acidic and basic functional groups on the carbon' surface of AKWs-BC were about 2.2 and 1.2 times that of TH-BC, respectively, which suggested that AKWs facilitated the creation of acidity and basicity on the surface of AKWs-BC because AKWs contain a large amount of $\mathrm{N}$ and $\mathrm{O}$.

XPS was used to identify surface functional groups of AKWs-BC and TH-BC. The peak fitting of $\mathrm{O} 1 \mathrm{~s}$ and $\mathrm{N} 1 \mathrm{~s}$ was performed by XPS-PEAK software. The oxygen functional groups on the surface of AKWs-BC exhibit three peaks in Figure 3: (O-I) $\mathrm{C}=\mathrm{O}$ groups (carbonyl and quinone) at $531.1 \pm 0.5 \mathrm{eV}$, (O-II) C-OH/C-O-C (hydroxyl ether ester and anhydride) at $533.1 \pm 0.5 \mathrm{Ev}$, and (O-III) $-\mathrm{COOH}$ at 535.8 $\pm 0.5 \mathrm{eV}$. The nitrogen functional groups on the surface of AKWs-BC presented two peaks in Figure 4: (N 6, Pyridine nitrogen and amino group) $-\mathrm{CONH}-/ \mathrm{N}-\mathrm{H}$ at $398.7 \pm 0.5 \mathrm{eV}$ or (N 5, pyrrole-like nitrogen) $-\mathrm{CONH}-/-\mathrm{NH}_{2}$ at $399.8 \pm 0.5 \mathrm{eV}$, while $-\mathrm{NO}_{2}$ represents nitrogen in nitro group (403.6-405.1 $\mathrm{eV})[6,7]$. The number of oxygen-containing and nitrogen-containing functional groups of AKWs-BC is higher than that of TH-BC, which is consistent with the results of Boehm's titration results and element composition. Overall, there is strong evidence that APWs promote the formation of functional groups on the surface of the AKWs-BC. 

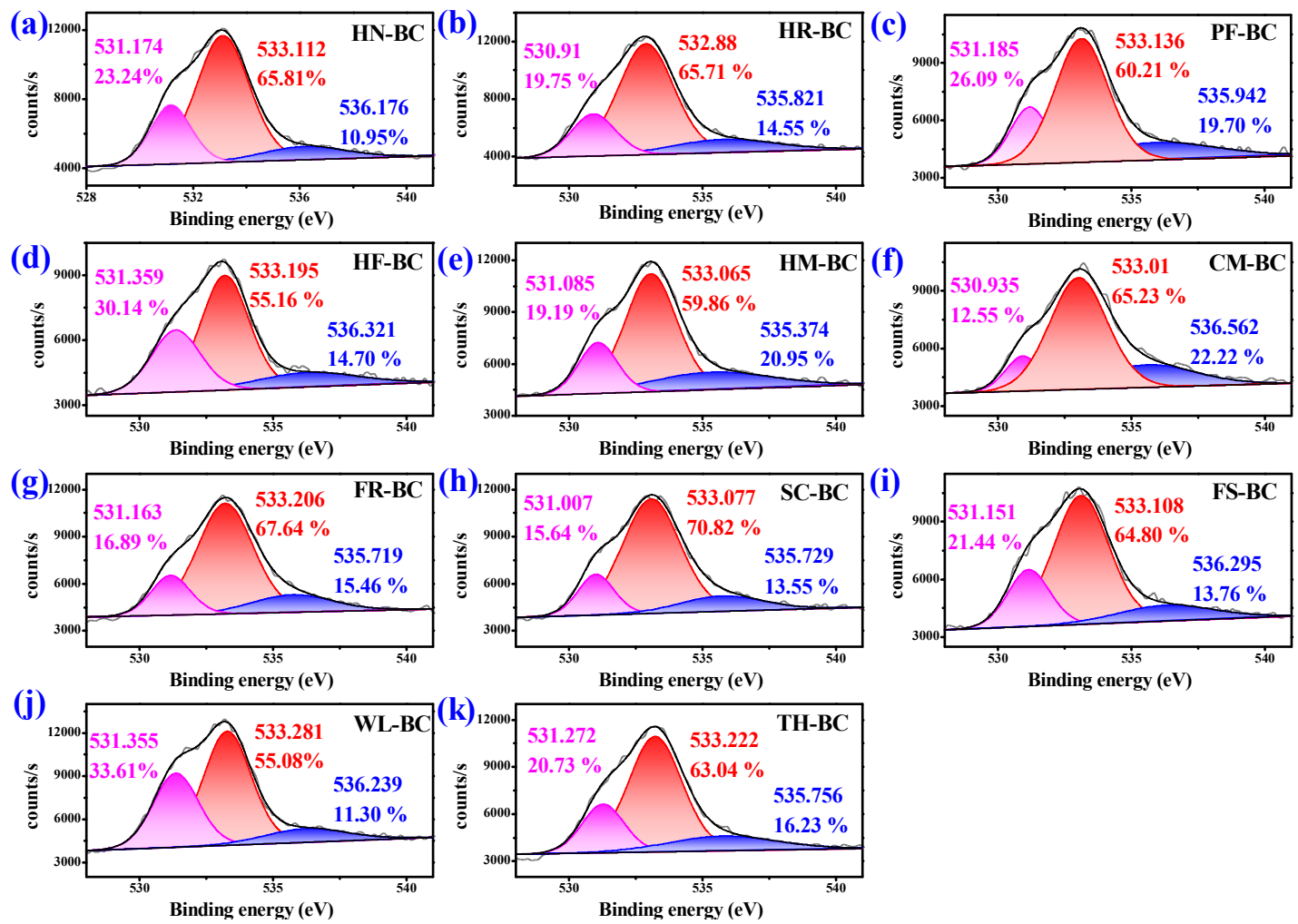

Figure 3. XPS (O 1s) spectra of AKWs-BC and TH-BC: HN-BC (a); HR-BC (b); PF-BC (c); HF-BC (d); HM-BC (e); CM-BC (f); FR-BC (g); SC-BC (h); FS-BC (i); WL-BC (j); TH-BC (k).
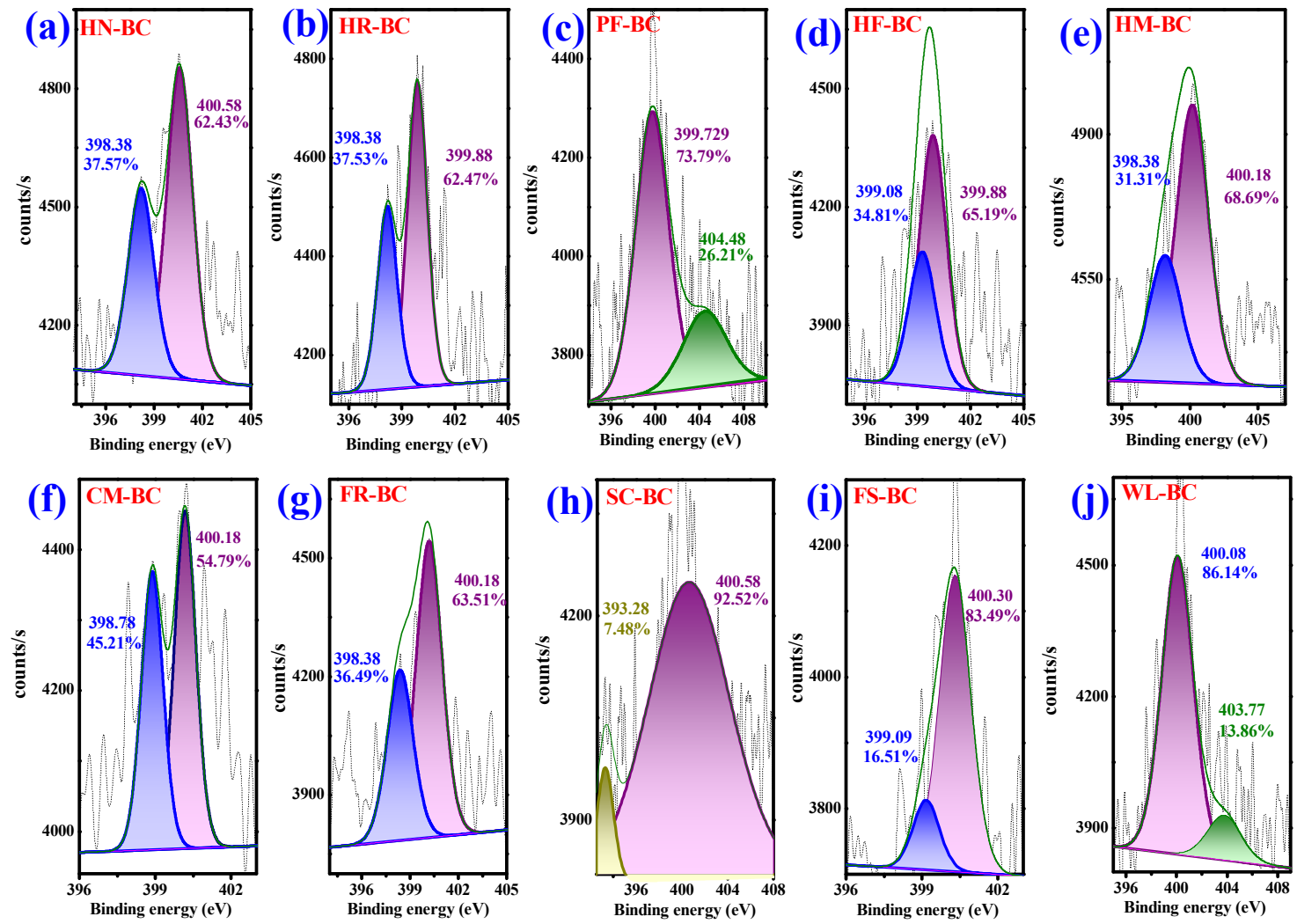

Figure 4. XPS spectra (N 1s) of AKWs-BC: HN-BC (a); HR-BC (b); PF-BC (c); HF-BC (d); HM-BC (e); CM-BC (f); FR-BC (g); SC-BC (h); FS-BC (i); WL-BC (j). 


\section{Conclusions}

The results show that it is feasible to use AKWs as a biochar modifier. AKWs-BC exhibits a developed microporous structure and high chemical functional groups. The use of APWs can not only realize the resource utilization of waste, it can also provide new ideas for biochar preparation modification.

Author Contributions: Writing—original draft, W.Y.; Conceptualization, W.Y. and Y.X.; Software, Z.Z. and S.X.; Data curation, T.L. and Z.Z.; Formal analysis, T.L.; Supervision, J.X.; Investigation, S.X. and J.X. All authors have read and agreed to the published version of the manuscript.

Funding: This research received no external funding.

Acknowledgments: This work was supported by the UN Environment-Tongji Institute of Environment for Sustainable Development (IESD).

Conflicts of Interest: The authors declared no potential conflicts of interest with respect to the research, authorship, and/or publication of this article.

\section{References}

1. Han, Y.; Cao, X.; Ouyang, X.; Sohi, S.; Chen, J. Adsorption kinetics of magnetic biochar derived from peanut hull on removal of $\mathrm{Cr}(\mathrm{VI})$ from aqueous solution: Effects of production conditions and particle size. Chemosphere 2016, 145, 336-341. [CrossRef] [PubMed]

2. Ruan, Z.-H.; Wu, J.; Huang, J.-F.; Lin, Z.; Li, Y.-F.; Liu, Y.-L.; Cao, P.-Y.; Fang, Y.-P.; Xie, J.; Jiang, G. Facile preparation of rosin-based biochar coated bentonite for supporting $\alpha-\mathrm{Fe}_{2} \mathrm{O}_{3}$ nanoparticles and its application for $\mathrm{Cr}$ (vi) adsorption. J. Mater. Chem. A 2015, 3, 4595-4603. [CrossRef]

3. Aluigi, A.; Tonetti, C.; Vineis, C.; Tonin, C.; Mazzuchetti, G. Adsorption of copper(II) ions by keratin/PA6 blend nanofibres. Eur. Polym. J. 2011, 47, 1756-1764. [CrossRef]

4. Chen, B.; Xing, Y.; Yu, W.; Liu, H. Wool keratin and silk sericin composite films reinforced by molecular network reconstruction. J. Mater. Sci. 2017, 53, 5418-5428. [CrossRef]

5. Kong, J.; Yue, Q.; Huang, L.; Gao, Y.; Sun, Y.; Gao, B.; Li, Q.; Wang, Y. Preparation, characterization and evaluation of adsorptive properties of leather waste based activated carbon via physical and chemical activation. Chem. Eng. J. 2013, 221, 62-71. [CrossRef]

6. Liu, Y.; Sohi, S.; Liu, S.; Guan, J.; Zhou, J.; Chen, J. Adsorption and reductive degradation of $\mathrm{Cr}(\mathrm{VI})$ and TCE by a simply synthesized zero valent iron magnetic biochar. J. Environ. Manag. 2019, 235, 276-281. [CrossRef] [PubMed]

7. Li, M.; Liu, H.; Chen, T.; Dong, C.; Sun, Y. Synthesis of magnetic biochar composites for enhanced uranium(VI) adsorption. Sci. Total. Environ. 2019, 651, 1020-1028. [CrossRef] [PubMed]

(C) 2020 by the authors. Licensee MDPI, Basel, Switzerland. This article is an open access article distributed under the terms and conditions of the Creative Commons Attribution (CC BY) license (http://creativecommons.org/licenses/by/4.0/). 